\title{
PRODUCTION, PURIFICATION, AND CHARACTERIZATION OF BIOACTIVE METABOLITES PRODUCED FROM RARE ACTINOBACTERIA PSEUDONOCARDIA ALNI
}

\author{
RABAB OMRAN ${ }^{1 *}$, MOHAMMED FADHIL KADHEM ${ }^{2}$
}

${ }^{1}$ Department of Biology, College of Science, University of Babylon, Babel, Al-Hillah, Iraq. ${ }^{2}$ Department of Pharmacology, Ibn Hayyan College, Karbala, Iraq. Email: omranaljelawi@gmail.com, sci.rabab.omran@uobabylon.edu.iq

Received: 30 August 2016, Revised and Accepted: 12 September 2016

\section{ABSTRACT}

Objectives: Pseudonocardia alni exhibits antimicrobial activity against tested pathogenic Staphylococcus aureus, Microsporum canis, and Trichophyton mentagrophyte. The present paper aimed to optimize various cultural conditions for antimicrobial metabolite production, purification, and characterization of the active substance.

Methods: The effects of various parameters such as culture media, carbon and nitrogen sources, phosphate concentration, $\mathrm{pH}$, temperature, incubation period, and agitation rate on bioactive metabolite production were studied using a flask scale with varying single parameter. The active substances were purified by adsorption chromatography using Silica gel column and Sephadex LH 20 column, and the physical, chemical, and biological properties were characterized.

Results: The metabolite production by P. alni was greatly influenced by various cultural conditions. It produced high levels of the antimicrobial substance in International Streptomyces project- 2 broth compared with that in potato dextrose broth. The optimum parameters for antimicrobial production from the actinobacterium occurred in the production medium consisting of glucose (1\%) and tryptone $(1 \%), 0.001 \mathrm{M}$ of $\mathrm{K}_{2} \mathrm{HPO}_{4}$ and $0.05 \mathrm{M}$ glycine at initial $\mathrm{pH} 8.5$ and incubated at $30^{\circ} \mathrm{C}$ for $4 \mathrm{~d}$ in stand incubator. The higher concentration of phosphate buffer salts ( $\left.>0.01 \mathrm{M}\right)$ repressed the bioactive production. The purified active substance had relative factor $\mathrm{R}_{\mathrm{f}}=0.53$ in the mobile phase of a thin layer chromatography system and the maximum absorbance $(\lambda \max )$ at $216 \mathrm{~nm}$. The results of infrared spectra Fourier transform-infrared spectroscopy analysis indicate that it may be regarded to glycopeptide antibiotic. The purified substance had antibacterial and antifungal activities as well as cytotoxic activity in breast cancer cell line Michigan Cancer Foundation-7 and normal hepatic cell line (WRL-68) at a percentage up to 23.7\% and 7.64\%, respectively.

Conclusions: The actinobacterium P. alni was a novel strain having the ability to produce antimicrobial and anticancer substances.

Keywords: Pseudonocardia alni, Antifungal-antibacterial, Anticancer optimization, Production, Purification, Characterization.

(C) 2016 The Authors. Published by Innovare Academic Sciences Pvt Ltd. This is an open access article under the CC BY license (http://creativecommons. org/licenses/by/4. 0/) DOI: http://dx.doi.org/10.22159/ajpcr.2016.v9s3.14961

\section{INTRODUCTION}

Most of the antimicrobial drugs in use today are derivatives of natural products of actinomycetes and fungi. Antibiotics produced by microorganisms have been evolving for one billion years [1]. The activity of antibiotics is estimated against pathogenic microbes based on their ability to inhibit target macromolecules and biosynthesis pathways. On the other hand, these microorganisms develop resistance systems to survive, therefore the screenings for the new antimicrobial producer are endless [2,3]. Although the successive discoveries of antibiotics resulted in increasing the number of known antibiotics reaching to 22500 , only about 150 antibiotics are in direct use in the human and veterinary treatment and agricultural applications. About $45 \%$ of these metabolites are produced from actinomycetes such as Streptomyces sp. comprising $74 \%$ and the rest containing other actinomycetes species and rare actinobacteria [4]. Antibiotic production by microbial strains can be significantly influenced by different nutrition and cultivation conditions. Therefore, the medium constitutions together with the metabolic capacity of the producing microorganism greatly have an impact on bioactive metabolite synthesis. Several environmental factors, such as temperature, $\mathrm{pH}$, aeration, agitation, and incubation period, play a major role in the production of antimicrobial agents $[5,6]$ In a previous study, Pseudonocardia alni as a rare actinobacterium was isolated from a soil sample, which was identified depending on cultural, physiological, and biochemical characteristics. This isolate had the ability to produce antifungal and antibacterial metabolites [7]. The objectives of this study were formulating a production medium and optimizing the fermentation conditions to achieve the maximum yield of antibiotic production from the rare actinobacterium $P$. alni, as well as purification and characterization of an antimicrobial substance.

\section{METHODS}

\section{Bacterial strains}

P. alni was previously isolated from soil in Biotechnology Laboratory at Babylon University, Iraq [7], and it had the ability to produce antimicrobial substances against pathogenic bacteria and fungi, including Staphylococcus aureus, Escherichia coli, Morganella morganii, Microsporum canis, and Trichophyton mentagrophyte [7]. The pure cultures were maintained in AMES medium at $4^{\circ} \mathrm{C}$ for further studies.

Pathogenic isolates S. aureus and T. mentagrophyte were obtained from Biotechnology Laboratory to use as a test organism in all experiments which were performed in the same laboratory at Babylon University.

\section{Optimization of production parameters}

The effect of various parameters, including culture media, carbon and nitrogen sources, phosphate concentration, $\mathrm{pH}$, temperature, incubation times, and an agitation rate of production medium, on bioactive metabolite production, was studied by varying a single parameter at a time. All experiments were performed in $250 \mathrm{ml}$ conical flasks, each one containing $50 \mathrm{ml}$ of variant tested medium in 
triplicate. All media were sterilized by autoclave at $121^{\circ} \mathrm{C}$ for $20 \mathrm{~min}$ The flasks were inoculated with $1 \mathrm{ml}$ of $P$. alni inoculum. The inoculum was prepared as a seed culture that was grown under optimal growth conditions (International Streptomyces project [ISP-2] broth at pH8 and incubated at $30^{\circ} \mathrm{C}$ for $3 \mathrm{~d}$ ).

\section{Production media formulation}

P. alni was grown separately in two sterilized media, the first, potato dextrose broth (PDB) which was prepared from $2 \%$ glucose and $20 \%$ potato extract $(20 \mathrm{~g}$ of potato slice boiled in $90 \mathrm{ml}$ distilled water (DW) for $10 \mathrm{~min}$, after cooling to room temperature, it was filtrated, the supernatant was supplemented with 2 g glucose, and finally the $\mathrm{pH}$ was adjusted to 7.5 using phosphate buffer salts $\left(\mathrm{K}_{2} \mathrm{HPO}_{4}\right.$ and $\mathrm{KH}_{2} \mathrm{PO}_{4}$ to reach final concentration $0.01 \mathrm{M}$, and the volume was completed to $100 \mathrm{ml}$ with DW). The second medium, yeast extract-malt extract broth, which was prepared according to the ISP-2, ISP-2 broth comprised $0.4 \%$ glucose, $1 \%$ yeast extract, and $0.4 \%$ malt extract dissolved in 0.01 $\mathrm{M}$ of phosphate buffer at $\mathrm{pH} 7.5[6,8]$. Both media were inoculated with $1 \mathrm{ml}$ of a seed culture aged $3 \mathrm{~d}$ and then incubated at $30^{\circ} \mathrm{C}$ for $7 \mathrm{~d}$. After that, the cell-free filtered supernatant was separated from the culture broth by cooling centrifugation at $8000 \times \mathrm{g}$ for $10 \mathrm{~min}$, and then it was filtered by Millipore filter $(0.22 \mu \mathrm{m})$. Antagonistic activity of $P$. alni cultural filtrate was estimated against the pathogenic test organism by agar well diffusion method [9].

\section{Agar well diffusion method}

Agar well diffusion method was performed according to Perez et al. [9] using Mueller-Hinton agar (MHA) medium for S. aureus and PDA for T. mentagrophyte. The inoculum of the test organisms was prepared separately by mixing three microorganism colonies from the exponential phase with $10 \mathrm{ml}$ of sterile nutrient broth, and the turbidity was compared with that of the standard 0.5 McFarland solution which is equivalent to 106-108 CFU/ml. The sterile swab was dipped into suitably adjusted inoculum. The entire MHA and PDA surfaces were swabbed evenly by the cotton swab. The inoculated plates were left at room temperature for 3-5 min to absorb surface moisture before well formed. The wells ( $6.0 \mathrm{~mm}$ diameter, $2.0 \mathrm{~cm}$ apart) were formed in a medium using a sterile cork borer, and then $100 \mu \mathrm{l}$ of culture filtered of P. alni containing $30 \mu \mathrm{g}$ of antimicrobial substance was loaded into each well for the assay of antagonistic activity. The plates were pre-incubated at $4^{\circ} \mathrm{C}$ for $2 \mathrm{~h}$ to allow uniform diffusion into the agar. Subsequently, the plates were incubated in suitable conditions for test organisms' growth, at $37^{\circ} \mathrm{C}$ for $18 \mathrm{~h}(S$. aureus) and $28^{\circ} \mathrm{C}$ for $3 \mathrm{~d}$ (T. mentagrophyte). The antimicrobial activity was evaluated by measuring inhibition zone diameter.

\section{Carbon and nitrogen sources}

The effects of carbon sources, including xylose, inositol, arabinose, raffinose, fructose, glucose, and sucrose were studied by adding $1 \%$ of sterilized sugars separately into the best-sterilized production medium at $\mathrm{pH}$ 7.5; subsequently, they were inoculated with $1 \mathrm{ml}$ of a seed culture of $P$. alni aged $3 \mathrm{~d}$ and incubated at $30^{\circ} \mathrm{C}$ for $7 \mathrm{~d}$. After a suitable carbon source was determined, different nitrogen sources (1\%) such as ammonium chloride, ammonium phosphate, potassium nitrate, peptone, yeast extract, tryptone, and malt extract were studied at the same patterns, each carbon and nitrogen source was performed in triplicate $[3,4]$. Antimicrobial activity of fermentation filtrates was tested by agar well diffusion method [9].

\section{Effect of phosphate buffer concentrations on antimicrobial production}

ISP-2 broth was prepared with different concentrations of phosphate buffer at pH 7.5, including 0.001, 0.01, 0.025, 0.05, 0.1, and 0.2 M. In addition, glucose tryptone broth (GTB) was used as a control medium consisting of $1 \%$ glucose and $1 \%$ tryptone which were dissolved in $0.001 \mathrm{M}$ phosphate buffer $[3,4]$. Each one, in triplicate, was inoculated with $1 \mathrm{ml}$ of a seed culture of P. alni aged $3 \mathrm{~d}$ and incubated at $30^{\circ} \mathrm{C}$ for $7 \mathrm{~d}$. After that, the antimicrobial activity of the filtrates was tested by agar well diffusion method [9].

\section{Initial $\mathrm{pH}$ of production medium}

The optimal initial $\mathrm{pH}$ of the medium for maximum antibiotic production was determined by preparing fermentation media, in triplicate, with $0.05 \mathrm{M}$ available buffer, including citrate buffer at $\mathrm{pH} 6$

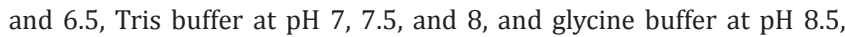
$9,9.5$, and $10[3,4]$. Fermentation media were inoculated with $1 \mathrm{ml}$ of a seed culture of $P$. alni aged $3 \mathrm{~d}$ and incubated at $30^{\circ} \mathrm{C}$ for $7 \mathrm{~d}$. The antimicrobial activity of fermentation filtrates was tested by agar well diffusion method [9].

\section{Optimum incubation temperature}

To determine the optimum temperature for antibiotic production, the optimal fermentation media in triplicate were inoculated with $1 \mathrm{ml}$ of a seed culture of $P$. alni aged $3 \mathrm{~d}$ and incubated at different temperatures from $20^{\circ} \mathrm{C}$ to $50^{\circ} \mathrm{C}$ with an interval of $5^{\circ}$ for $7 \mathrm{~d}[5,6]$. The antimicrobial activity of fermentation filtrates was determined by agar well diffusion method [9].

\section{Optimum incubation period}

Optimal period of antibiotic production was determined by inoculating optimal fermentation media, in triplicate, with $1 \mathrm{ml}$ of a seed culture of P. alni aged $3 \mathrm{~d}$ and incubated at $30^{\circ} \mathrm{C}$ for $10 \mathrm{~d}[5,6]$. The antimicrobial activity of fermentation filtrates was tested every day by agar well diffusion method [9].

\section{Agitation}

The effect of shaking rate of fermentation media was studied after determined the incubation period. in triplicate, at shaker incubator in different shaking rotations ranging from 40 to $200 \mathrm{rpm}$, also it is incubated at the stand incubator under optimum fermentation parameters. The antimicrobial activity of fermentation filtrates was assayed by agar well diffusion method [9]

\section{Thermal stability of the antimicrobial substance}

Thermal stability determination is very important to facilitate the extraction, purification, and storing of antimicrobial substances. Thermal stability of the crude antimicrobial substance was investigated by storing it at various temperatures ranged from $0^{\circ} \mathrm{C}$ to $100{ }^{\circ} \mathrm{C}$ for 1 $\mathrm{h}$; after that, the antimicrobial activity was assayed to determine the percentage of residual activity.

\section{Antimicrobial substance extraction}

The antimicrobial substance $(1000 \mathrm{ml})$ was produced under optimal production parameters. The cultural filtrate containing the antimicrobial activity was separated from biomass by filtration using Whatman No. 1 with vacuum, after that, it was filtrated by the $45 \mu \mathrm{m}$ Millipore filter. The cultural filtrate as a crude antimicrobial substance was concentrated by rotary evaporator at $60^{\circ} \mathrm{C}$ for 1 $\mathrm{h}$ until it became a viscous or gummy agent. The antimicrobial substances were extracted from the concentrated gummy agent by different solvents such as ethyl acetate, ethanol, methanol, acetone, chloroform, and hexane, in addition to using DW and glycine buffer. Each $5 \mathrm{ml}$ of the solvent was added into $1 \mathrm{ml}$ of concentrated gummy agent separately and vigorously mixed for $5 \mathrm{~min}$, and then it was centrifuged. The supernatant was separated from the gummy agent, and the antimicrobial activities were assayed for both fractions. Subsequently, the best extraction solvent was selected for extracting the antimicrobial substance, and the active fraction was concentrated by rotary evaporator at $60^{\circ} \mathrm{C}$. The concentrated antimicrobial extract was stored at $-20^{\circ} \mathrm{C}$ until it was purified by column adsorption chromatography.

\section{Purification of antimicrobial substance by column adsorption chromatography}

The antimicrobial extract was purified by two steps of column adsorption chromatography using silica gel (60-120 mesh) and Sephadex LH 20 gel, respectively. Silica gel $(20 \mathrm{~g})$ was prepared according to Pavia et al. [10] using hexane and poured into the column 
$(1.6 \times 14 \mathrm{~cm})$, after the setting of $2 \mathrm{ml}$ of concentrated antimicrobial extract (containing $20 \mathrm{mg}$ substance) was loaded onto the column and washed with $30 \mathrm{ml}$ of hexane, $30 \mathrm{ml}$ of chloroform, $45 \mathrm{ml}$ of absolute methanol. The fractions were collected at a volume of $3 \mathrm{ml} /$ fraction at a flow rate of $25 \mathrm{ml} / \mathrm{h}$. The absorbance was measured at $280 \mathrm{~nm}$, and antimicrobial activity was assayed for each fraction. The active fractions were combined and concentrated by rotary evaporator to more purification by the next step.

The Sephadex LH 20 column was prepared according to the instruction of the Amersham Biosciences company. About $15 \mathrm{~g}$ of the Sephadex LH 20 was suspended in $58 \mathrm{ml}$ ethanol for $3 \mathrm{~h}$ to swollen, and the prepared gel was vacuumed for degassing and poured into the column $(1.6 \times 20 \mathrm{~cm})$. After column setting, it was washed with absolute ethanol and the flow rate was calculated. A volume of $2 \mathrm{ml}$ of the concentrated antimicrobial substance containing $10 \mathrm{mg}$ substance obtained from the previous step was loaded into a column and then the column was washed with $60 \mathrm{ml}$ absolute ethanol to remove undesired materials. After that, the adsorbent active substance onto the gel was eluted with $90 \mathrm{ml}$ of absolute methanol at a flow rate of $12 \mathrm{ml} / \mathrm{h}$ and fractional volume of $3 \mathrm{ml} /$ fraction. The absorbance was measured at $280 \mathrm{~nm}$, and antimicrobial activity was assayed for each fraction. The active fractions were combined and concentrated by rotary evaporator and stored at $-20^{\circ} \mathrm{C}$ for characterization.

\section{Characterization of partial purified antimicrobial agent Physical characteristics}

Physical characteristics of the partial purified antimicrobial substance were studied including the color and solubility by solvents (water, methanol, ethanol, acetone, chloroform, ethyl acetate, and hexane). In addition, the melting point was determined using Stuart SMP30 apparatus (at Organic Chemistry Lab., Chemistry Department, College of Science, University of Babylon).

\section{Thin layer chromatography (TLC)}

TLC was performed on an aluminum foil [10], which was coated with silica gel; three solvent systems were used separately. The first one - butanol:acetic acid: $\mathrm{H}_{2} \mathrm{O}$ (3:5:7), the second system chloroform:dichloromethane:ethyl acetate (3:5:7), and the third system - ethyl acetate:toluene:n-Hexane (3:5:7). After running, the plates were dried at room temperature. The plates were kept in a TLC chamber containing iodine pellets and they were visualized under visible and ultraviolet (UV) light for fluorescence. Relative factor $\left(\mathrm{R}_{\mathrm{f}}\right)$ was determined using the following equation:

$\mathrm{R}_{\mathrm{f}}$ value=movement of solute/movement of solvent.

\section{Chemical characteristics}

Two chemical tests were performed to detect the presence of carbohydrate moiety and peptide moiety within purified antimicrobial molecules including Molisch's test and Biuret test.

\section{Molisch's test}

This test is a sensitive chemical test for the presence of carbohydrates, based on the dehydration of the carbohydrate by sulfuric acid to produce an aldehyde, which condenses with two molecules of phenol (usually $\alpha$-naphthol), resulting in a red- or purple-colored compound. About $1 \mathrm{ml}$ of purified antimicrobial substance was combined with a small amount of Molisch's reagent ( $\alpha$-naphthol dissolved in ethanol) in a test tube. After mixing, a small amount of concentrated sulfuric acid is slowly added down the sides of the sloping test tube, without mixing, to form a layer. A positive reaction is indicated by the appearance of a purple ring at the interface between the acid and test layers [11].

\section{Biuret test}

This test is a chemical test used for detecting the presence of peptide bonds within antimicrobial molecules. In the presence of peptides, a copper (II) ion forms violet-colored coordination complexes in an alkaline solution [1]. About $0.1 \mathrm{~g}$ of gummy purified antimicrobial substance was dissolved with $3 \mathrm{ml}$ of $10 \%$ sodium hydroxide, followed which three drops of aqueous copper (II) sulfate was added. If the solution turns purple, it indicates that the test is positive [11].

\section{Spectroscopic characteristics} UV light spectra measurement

A small amount of purified antimicrobial substance was dissolved in methanol, and the spectroscopic characteristic was determined at a range of 200-800 $\mathrm{nm}$ using Shimadzu UV-Visible spectrophotometer 1601 (Chemistry Department, University of Babylon).

\section{Infrared spectra measurement}

This analysis was performed at Chemistry Department, ALMustansiriyah University. IR spectra of purified antimicrobial substance were measured by Perkin Elmer 2000 Fourier TransformInfrared Spectroscopy using a $\mathrm{KBr}$ discs technique at a range of $600-4000 \mathrm{~cm}^{-1}[12]$.

\section{Cytotoxicity activity determination by MTT Assay}

To determine the cell viability by colorimetric assay using 3-[4, 5 - dimethylthiazol] -2, 5-diphenyltetrazolium bromide (MTT dye), two kinds of cells were employed in this work: The human breast cancer cell line (Michigan Cancer Foundation [MCF-7] cell line) and the normal human hepatic cells (non-tumorigenic fetal hepatic cell line WRL-68). Briefly, $100 \mu \mathrm{l}$ cell suspension was added to the flat-bottomed microculture plate wells, each cell line was examined in a separate plate and they were treated with $100 \mu \mathrm{l}$ antimicrobial extract, incubated for $24 \mathrm{~h}$, centrifuged to remove the dead cells. An aliquot of $100 \mu \mathrm{l}$ from $2 \mathrm{mg} / \mathrm{ml}$ MTT dye was added to each well and the incubation was continued for a further $4 \mathrm{hrs}$, and then $50 \mu \mathrm{l}$ of solubilization solution of dimethyl sulfoxide was added to each well. The experiment was performed in triplicate. After complete solubilization of the dye, the absorbance of the colored solution obtained from living cells was read at $620 \mathrm{~nm}$ with an ELISA reader. The mean absorbance for each group of replicate was calculated. The percentage viability of cells exposed to various treatments was obtained as follows $[13,14]$

$\%$ cell viability $=[($ mean absorbance of treated samples $/$ mean absorbance of non-treated sample) $\times 100]$

The control was the non-treated cultures in all experiments that contained cells in the medium only. This assay was held at the Centre for Natural Product Research and Drug Discovery, Department of Pharmacology, Faculty of Medicine, University of Malaya/Kuala Lumpur, Malaysia.

\section{Statistical analyses}

Data were evaluated by one-way analysis of variance using Statgraphics Plus 4.0 (Manugistics, Inc., Rockville, USA) software. $t$-test was performed to determine significant differences at $\mathrm{p}<0.05$.

\section{RESULTS AND DISCUSSION}

Pseudonocardia strains were the bioactive rare actinobacteria which have the ability to produce antimicrobial metabolites using different primary screening media [7] and extracellular enzymes and antimicrobial metabolites produced at stationary phase of bacterial growth, which started after 4 days and suppressed gradually after nine days $[7,15]$. The present study deals with optimizing antimicrobial production conditions as cultural media, carbon and nitrogen sources, phosphate buffer concentration, $\mathrm{pH}$, temperature, incubation period, and agitation of production medium. The antimicrobial activity was estimated according to agar well diffusion method using Gram-positive pathogenic bacteria $S$. aureus and pathogenic fungus T. mentagrophyte as test microorganisms. The results revealed that the best production 
medium for higher antibiotics yield from P. alni was ISP-2 in comparison with PDB depending on inhibition zone diameter. The supernatant filtrate of ISP- 2 culture had antagonistic activities (17 and $16 \mathrm{~mm} / 30 \mu \mathrm{g}$ of antimicrobial substance) against $S$. aureus and T. mentagrophyte, respectively, and it was more than PDB culture $(14$ and $16 \mathrm{~mm} / 30 \mu \mathrm{g}$ of antimicrobial substance). These variations occurred because of both media containing different compositions, ISP-2 broth composing from $0.4 \%$ glucose, $1 \%$ yeast extract, and $0.4 \%$ malt extract was more nutritive in respect to nitrogen source $[6,8]$ whereas PDB was prepared from $2 \%$ glucose and $20 \%$ potato extract which has more carbon source than nitrogen source. Therefore, ISP-2 broth was used as a basal production medium in the subsequent experiments. These results were in agreement with Usha Kiranmayi et al. [6] who found that the ISP-2 medium was the most appropriate for antibiotic production from $P$. alni compared with other media.

\section{Production medium formulation}

To study the effect of carbon and nitrogen sources to formulate the production medium, seven sugars as carbon sources, including xylose, inositol, arabinose, raffinose, fructose, glucose, and sucrose were added to ISP-2 broth separately at $1 \%$ concentration as a substitute of $0.4 \%$ glucose at original medium. The results revealed that $1 \%$ glucose as sole carbon source stimulates increased $(p<0.05)$ the antimicrobial production more than other sugars, which showed less production in comparison with the original medium ISP-2 (Fig. 1a). These results were in agreement with other investigations of the researchers who stated that $1 \%$ glucose was the optimum carbon source for antibiotic production [16,17]. Furthermore, the higher concentrations of glucose (more than 1\%) could not display any effect on antibiotic production (data not showed) that indicated the antibiotic production from P. alni which may not adhere to catabolite repression control with increasing glucose concentrations $[6,16]$.

The results of influence of seven nitrogen sources (1\%) including ammonium chloride, ammonium phosphate, potassium nitrate, peptone, yeast extract, tryptone, and malt extract on the antibiotic production showed that $1 \%$ tryptone was the optimal nitrogen source $(\mathrm{p}<0.05)$ in addition to $1 \%$ glucose for supporting P. alni to produce a maximum antimicrobial yield in comparison with the original ISP-2 medium (consisting of $1 \%$ yeast extract, $0.4 \%$ malt extract, and $0.4 \%$ glucose) whereas the other nitrogen sources were less (Fig. 1b). Thus, the modified production medium GTB was composed of $1 \%$ tryptone as a vital nitrogen source and $1 \%$ glucose, which were used in the next experiments and these results approved with the other documentation references $[6,16]$.

After determining carbon and nitrogen sources (glucose and tryptone), another important factor for bacterial growth and antibiotic production representing a phosphate concentration was investigated. The effect of phosphate concentrations was surveyed by adding phosphate salts $\left(\mathrm{K}_{2} \mathrm{HPO}_{4}\right.$ and $\left.\mathrm{KH}_{2} \mathrm{PO}_{4}\right)$ to the original production medium (ISP-2) at different concentrations ranged from 0.001 to $0.2 \mathrm{M}$ in addition to modified GTB medium at a concentration of $0.001 \mathrm{M}$ for evaluation. The results revealed that the antibiotic production from $P$. alni was inhibited by phosphate salts when added at high concentrations $(\geq 0.025 \mathrm{M})$ into the media, whereas low phosphate concentrations $(0.001$ and $0.01 \mathrm{M})$ displayed less or non-observed influence on production (Fig. 2). Phosphate salt always has negative effects as an inhibitor of biosynthesis of many antibiotics such as aminoglycosides, peptide and polyene macrolide antibiotics, and others $[9,16,17]$. In addition, the high concentrations of phosphate buffer $(0.075-0.1 \mathrm{M})$ inhibited the production of cephalosporin from Streptomyces clavuligerus in spite of its stabilized $\mathrm{pH}$ of media and supported extensive actinobacterial growth [18]. Depending on these results, the modified production medium was supplemented with $0.001 \mathrm{M}^{\circ} \mathrm{K}_{2} \mathrm{HPO}_{4}$ for enhancing actinobacterial growth; in addition, it had no effect on antibiotic production, as well as the medium was supplemented with another buffer system for $\mathrm{pH}$ stabilization.

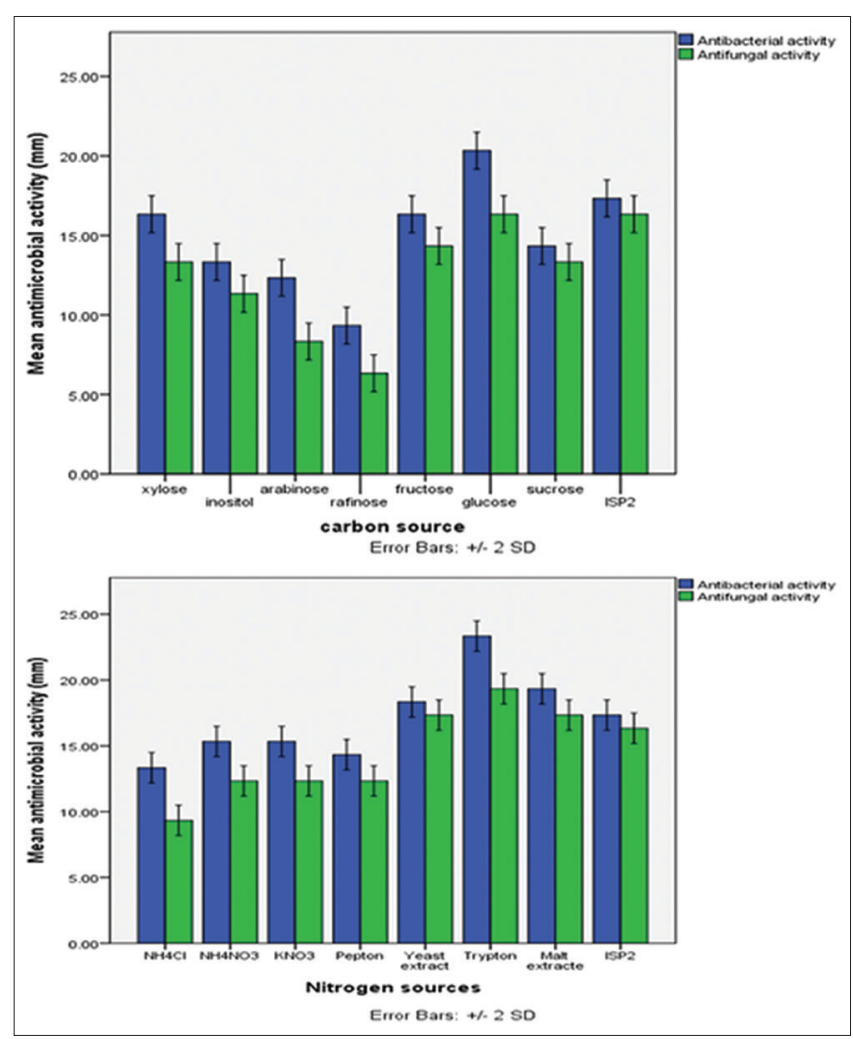

Fig. 1: Effect of carbon and nitrogen sources on antimicrobial production from Pseudonocardia alni. (a) The carbon sources $(1 \%)$ were supplemented into International Streptomyces project-2 broth separately at initial $\mathrm{pH} 7.5$; the actinobacterial strain was grown at $30^{\circ} \mathrm{C}$ for 7 days in stand incubator, (b) The nitrogen sources $(1 \%)$ were supplemented into International Streptomyces project-2 broth separately at an initial $\mathrm{pH}$ of 7.5 in addition to the medium containing $1 \%$ glucose as a carbon source; the actinobacterial strain was grown at $30^{\circ} \mathrm{C}$ for 7 days in stand incubator. Antimicrobial activity was performed using $100 \mu \mathrm{l}$ of filtered supernatant of Pseudonocardia alni culture containing $30 \mu \mathrm{g}$ of an antimicrobial substance

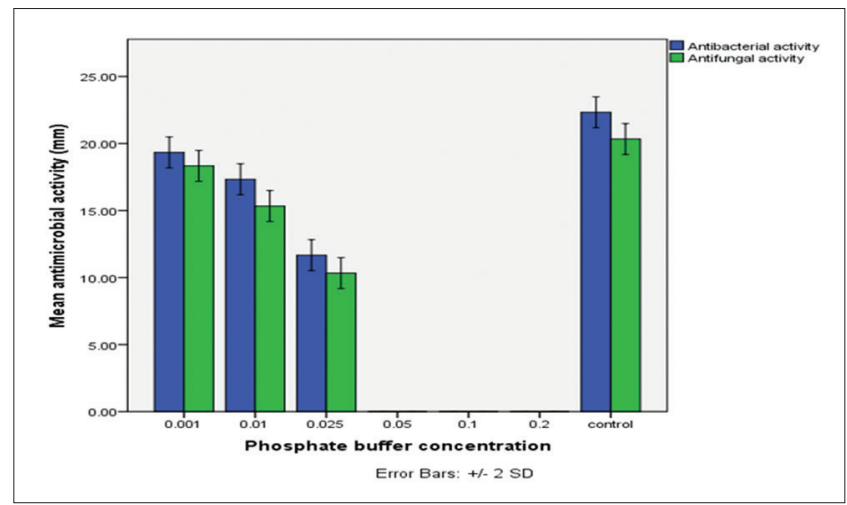

Fig. 2: The effect of phosphate buffer concentrations on antimicrobial production from Pseudonocardia alni. (1) The International Streptomyces project-2 broth was prepared at various concentrations of phosphate buffer broth in addition to modified medium glucose tryptone broth (containing $1 \%$ glucose and $1 \%$ tryptone) as control which was prepared in $0.001 \mathrm{M}$ phosphate buffer at initial pH 7.5; the actinobacterial strain was grown at $30^{\circ} \mathrm{C}$ for 7 days in stand incubator, (2) antimicrobial activity was performed using $100 \mu \mathrm{l}$ of the filtered supernatant of Pseudonocardia alni culture containing $30 \mu \mathrm{g}$ of an antimicrobial substance 
Initial pH of the media and incubation temperature

The effect of initial $\mathrm{pH}$ on antibiotic production was observed by adjusting the initial $\mathrm{pH}$ of the modified fermentation medium (GTB) in the range of 6-10 using $0.05 \mathrm{M}$ of available buffers and incubation of cultured media at a temperature of $30^{\circ} \mathrm{C}$ for $7 \mathrm{~d}$. The results showed that the isolate had the ability to produce the antibiotics at a $\mathrm{pH}$ range of 7-10 with the highest activity at a $\mathrm{pH}$ of 8.5 (Fig. 3a), whereas the production decreased with neutral and high alkaliphilic conditions. Depending on these results, the modified production medium (GTB) was supplemented with $0.05 \mathrm{M}$ of glycine buffer for initial $\mathrm{pH}$ which stabilizes at 8.5.

The productions of antibiotics depend on some production parameters such as the initial $\mathrm{pH}$ value of the medium and buffer salts and microorganism species. The effect of $\mathrm{pH}$ is ionizing the nutrients to facilitate uptake by microorganisms and to stimulate production pathways of antibiotics. Many researchers documented that the $\mathrm{pH}$ value of antibiotic production medium has different influences to guide the production toward positive or negative directions depending on the microorganism categories; in other words, any microorganism such as Streptomyces aburaviensis, Streptomyces violates, and Pseudonocardia needs optimal $\mathrm{pH}$ for highest antibiotic production, which had the maximum antibiotic yield at $\mathrm{pH}$ of $9,7.5$, and 7, respectively [5,6,17-23].

The present study showed that $P$. alni produced the antibiotic in a temperature range from $20^{\circ} \mathrm{C}$ to $40^{\circ} \mathrm{C}$ and the optimum temperature for maximum production was $30^{\circ} \mathrm{C}$, whereas it had no ability to produce the antibiotic at $50^{\circ} \mathrm{C}$ (Fig. $3 \mathrm{~b}$ ).

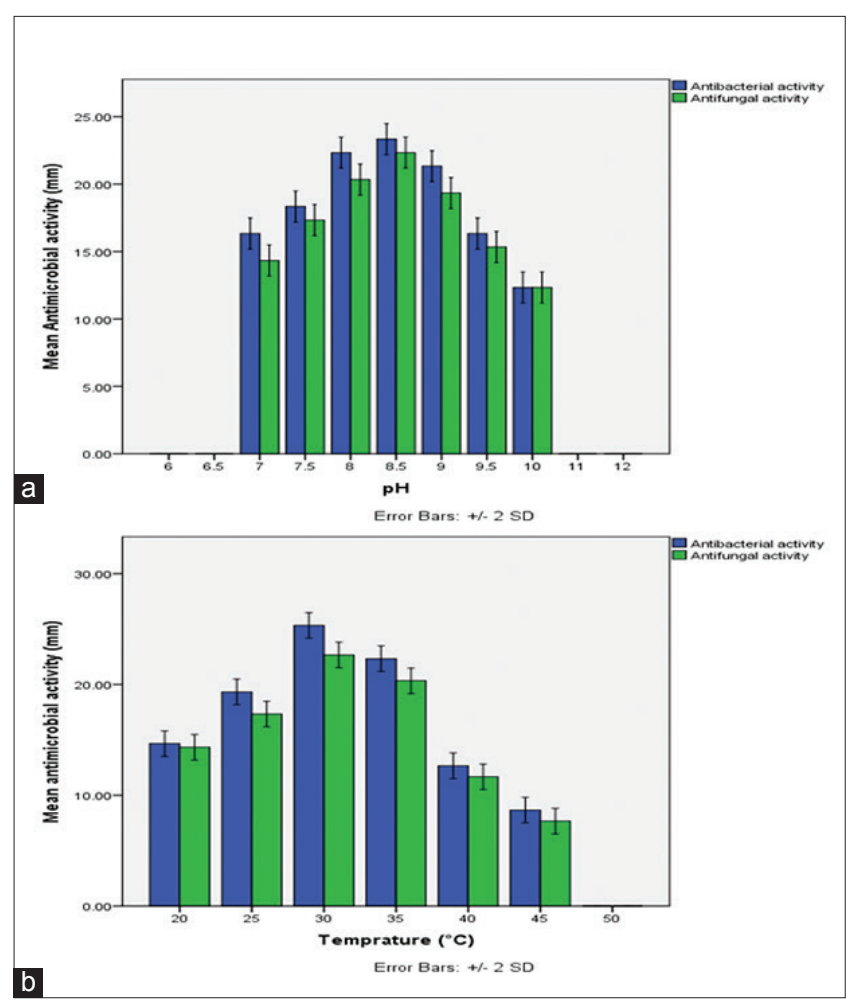

Fig. 3: The effect of $\mathrm{pH}$ and temperature on antimicrobial production from Pseudonocardia alni. (a) The modified medium glucose tryptone broth (containing 1\% glucose, 1\% tryptone, and $0.001 \mathrm{M} \mathrm{K}_{2} \mathrm{HPO}_{4)}$ was prepared at various initial $\mathrm{pH}$ values; the actinobacterial strain was grown at $30^{\circ} \mathrm{C}$ for $7 \mathrm{~d}$ in stand incubator, (b) The actinobacterial strain was grown at various temperatures into the modified medium glucose tryptone broth (containing $1 \%$ glucose, $1 \%$ tryptone, and $0.001 \mathrm{M} \mathrm{K}_{2} \mathrm{HPO}_{4 \text { ) }}$ at initial pH 8.5 for $7 \mathrm{~d}$ in stand incubator. Antimicrobial activity was performed using $100 \mu \mathrm{l}$ of filtered supernatant of Pseudonocardia alni culture containing $30 \mu \mathrm{g}$ of an antimicrobial substance
Many researchers reported that most of the actinobacterial species have the ability to produce maximum level of antibiotic productions at $30^{\circ} \mathrm{C}$ because these microorganisms were having an optimal growth at the same temperature similar to Streptomyces, $S$. violates, and also these organisms appeared to have poor growth and low level of antibiotic production at higher or lower optimum temperatures $[5,23]$. Other studies recorded various moderate temperatures up to $28^{\circ} \mathrm{C}$ and $35^{\circ} \mathrm{C}$ as the optimum temperatures for antibiotic production [6]. These results indicated that the optimum growth temperature leads to the huge biomass formation of actinobacterial cells that resulted in increasing antibiotic yield.

\section{Incubation period and agitation}

The antibiotic production starts through the $3^{\text {rd }}$ day and attains maximum at $5-7^{\text {th }}$ days, after that it declines (Fig. 4a). These results indicate that the antibiotics produced through the stationary phase when the microorganism enters the sporulation stage $[7,15]$.

These results in agreement with Usha Kiranmayi et al.'s [6] investigation revealed that the optimal period of antibiotic production from Pseudonocardia was the fourth day and the antimicrobial activity began to decline after the $5^{\text {th }}$ day until it became very weak on the $7^{\text {th }}$ day. In addition, Streptomyces which isolated from soil had the ability to produce antibiotic on the fourth day after that the production decreased [16].

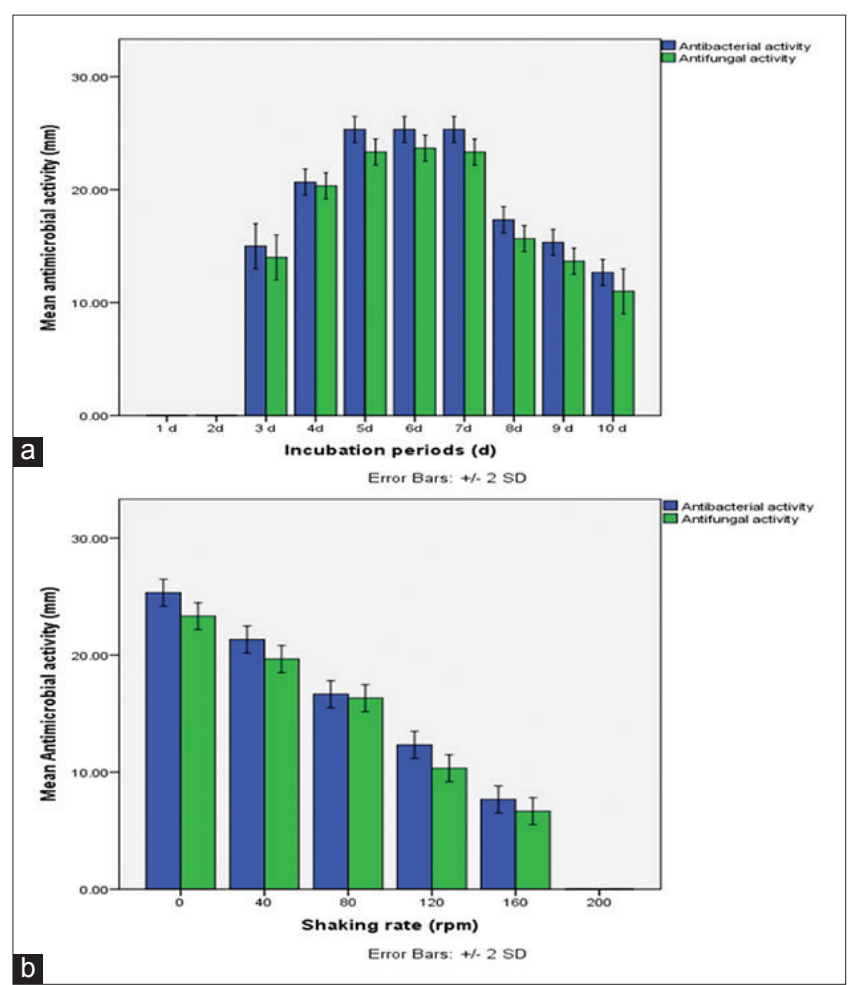

Fig. 4: The effect of the incubation period and agitation on antimicrobial production from Pseudonocardia alni. (a) The actinobacterial strain was grown into the modified medium glucose tryptone broth (containing $1 \%$ glucose, $1 \%$ tryptone, and $0.001 \mathrm{M} \mathrm{K}_{2} \mathrm{HPO}_{4}$ ) at initial $\mathrm{pH} 8.5$ at $30^{\circ} \mathrm{C}$ for various incubation periods in stand incubator, (b) The actinobacterial strain was grown into the modified medium glucose tryptone broth (containing $1 \%$ glucose, $1 \%$ tryptone, and $0.001 \mathrm{M}$ $\mathrm{K}_{2} \mathrm{HPO}_{4)}$ at initial $\mathrm{pH} 8.5$ at $30^{\circ} \mathrm{C}$ for $5 \mathrm{~d}$ in stand incubator and in shaking incubator at various shaking rotations. Antimicrobial activity was performed using $100 \mu \mathrm{l}$ of filtered supernatant of Pseudonocardia alni culture containing $30 \mu \mathrm{g}$ of an antimicrobial substance 
Antibiotic production from the microorganism in the present study was found to be influenced by the rotation speeds $120,150,200$, 220 , and $250 \mathrm{rpm}$ of shaker incubator (Fig. 4b). The maximum production was observed in standing condition. The antibiotic production reduced to half at rotation speeds $120 \mathrm{rpm}$ and $150 \mathrm{rpm}$ and completely repressed at $200 \mathrm{rpm}$. Thus, standing condition is more suitable for antibiotic production. These results were in agreement with El-Naggar et al. [23] who reported the highest production of antimicrobial substances by $S$. violates occurred after four days of incubation period under static conditions. Miyoshi et al. [24] who observed an increase in agitation led to the loss of antibiotic production, but a high level of production obtained at static condition.

The bioactive metabolites' purification and characterization Thermal stability of crude antimicrobial substance was measured before its extraction and purification by storing it at various temperatures ranged from $0^{\circ} \mathrm{C}$ to $100^{\circ} \mathrm{C}$ for $1 \mathrm{~h}$. The results revealed that the antimicrobial substance was thermally stable (100\% residual activity) at a temperature ranged from $0^{\circ} \mathrm{C}$ to $80^{\circ} \mathrm{C}$ and its residual activity declined to $90 \%$ at $100^{\circ} \mathrm{C}$ after storing for $1 \mathrm{hr}$. Many researchers had reported that the antimicrobial metabolites produced from actinobacterial species are thermally stable such as beta-lactam, oxacillin, ozloscine, and meziociline which toleranted autoclaving for $15 \mathrm{~min}$ [25].

The results of extraction appeared that the antimicrobial substance was not extracted from the concentrated gummy-cured filtrate using solvents such as hexane, ethyl acetate, and chloroform, whereas the water-miscible solvents such as acetone, ethanol, and methanol, in addition to glycine buffer and water appeared to have variable ability to extract the antimicrobial substance from the gummy concentrate of crude antibiotic. The best one was methanol at a ratio of 1:5 (Vol:Vol) of gummy crude product to absolute methanol that indicates that the antimicrobial substance was more soluble in methanol in comparison to the other water-miscible solvents and the methanol extract showed antimicrobial activity against both bacterial and fungal test organisms. The active fractions were collected together and concentrated for further purification by other chromatography methods. In addition, the strategy of purification by column adsorption chromatography using silica gel and Sephadex LH 20 gel was designed depending on the solubility of antimicrobial substances with used solvents above. When the antimicrobial substance ( $20 \mathrm{mg}$ dissolved in $2 \mathrm{ml}$ methanol) was loaded onto the silica gel column and washed with hexane and eluted with chloroform and absolute methanol, the separation results showed the presence of three peaks (Fig. 5a), one peak for each solvent, hexane and chloroform peaks had no antimicrobial activity, whereas the methanol peak showed antibacterial and antifungal activities. The partially purified antimicrobial showed higher activity $(25 \mathrm{~mm} / 35 \mu \mathrm{g}$ substance) compared with the crude filtrate $(20 \mathrm{~mm} / 35 \mu \mathrm{g}$ substance). The active fractions were combined for further purification, concentrated until drying, dissolved with $2 \mathrm{ml}$ absolute ethanol containing $10 \mathrm{mg}$ substance, and loaded into Sephadex LH 20 column using absolute ethanol for loading and washing the column with absolute methanol for antimicrobial elution. The results showed the presence of two peaks (Fig. 5b), one at washing solvent and one at eluted solvent. Ethanol peak had no antimicrobial activity, whereas methanol peak had the activity of both antibacterial and antifungal and showed higher activity ( $30 \mathrm{~mm} / 35 \mu \mathrm{g}$ substance) than the previous step.

Many researchers used different solvents for antibiotic extraction and these antibiotics showed variable ability to dissolve within solvents depending on their structures, compositions, and having hydrophilic or hydrophobic groups, however the antibiotic related to glycopeptide group has higher solubility in high polar solvents such as methanol, ethanol, and acetone but not with low or moderate polarity of solvents such as chloroform or ethyl acetate [26], as well as some of the antibiotics attributed to aminoglycoside group which isolated from actinomycetes are soluble in methanol or any high polarity solvent,

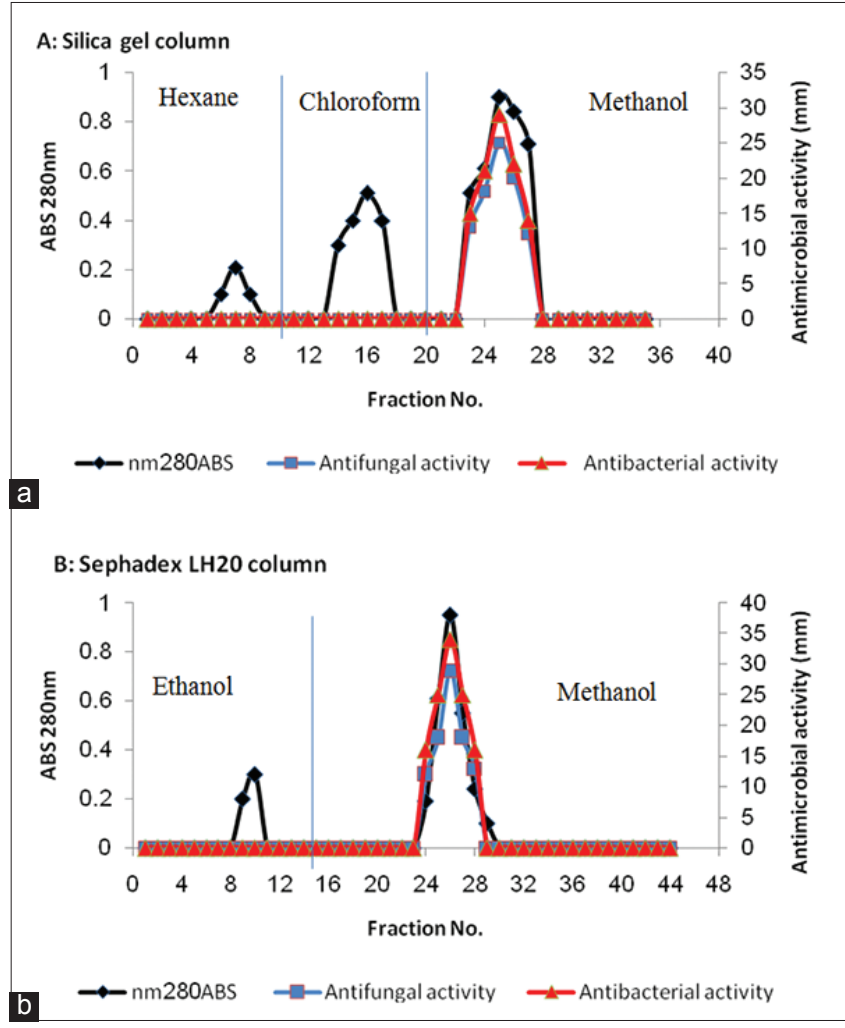

Fig. 5: The antimicrobial substance purification by adsorption chromatography using the silica gel column and Sephadex LH 20 column. (a) The silica gel column $(1.6 \times 14 \mathrm{~cm})$ was loaded by $2 \mathrm{ml}$ sample containing $20 \mathrm{mg}$ dry substance and it was washed with hexane and chloroform and eluted with methanol at a flow rate of $24 \mathrm{ml} / \mathrm{h}$ and the fractional volume was $3 \mathrm{ml} /$ fraction, (b) The Sephadex LH20 column $(1.6 \times 20 \mathrm{~cm})$ was loaded by $2 \mathrm{ml}$ sample containing $10 \mathrm{mg}$ dry substance and it was washed with ethanol and eluted by methanol at a flow rate of $12 \mathrm{ml} / \mathrm{h}$ and the fractional volume was $3 \mathrm{ml} /$ fraction

whereas some antibiotics more soluble with moderate polarity solvent such as ethyl acetate $[6,27]$. There are many procedures for antibiotic purification using different techniques depending on chromatography methods such as high-performance liquid chromatography or adsorption chromatography using silica gel and Sephadex LH20 gel. Oskay [26] reported that the glycopeptide antibiotic which produced from Streptomyces was purified using a silica gel column and followed by the Sephadex LH 20 column and eluted with methanol as the end step and reached a high level of antibiotic purification (semi homogenize). As well as some of the antibiotics produced from Pseudonocardia were purified using silica gel column and Sephadex LH 20 column [28].

\section{Antimicrobial characterization}

The purified antimicrobial substance had a yellow, non-crystal texture, high solubility with methanol, ethanol, and water, but not with hexane, chloroform, and ethyl acetate. The melting point of the partially purified antimicrobial substance was $300^{\circ} \mathrm{C}$ and black material remained after this test. It gave a positive reaction with Molisch's and Biurte tests that indicate the antimicrobial substance containing carbohydrate moiety and peptide moiety, and the antimicrobial substance may be related to aminoglycoside or glycopeptide groups [11].

The results of TLC showed the purified antimicrobial which had one spot with a relative factor $R_{f}=0.53$ (Fig. 6) which was separated in only one mobile system composed from butanol:acetic acid:water (3:5:7), but not with the other used systems, including the system chloroform: 
dichloromethane: ethyl acetate and the system ethyl acetate: toluene: hexane which were used in the ratio of 3:5:7 (Vol:Vol:Vol).

Spectroscopic characteristics of the purified antimicrobial substance revealed that it had an absorbance at UV light region with maximum absorbance ( $\lambda \max )$ at $216 \mathrm{~nm}$ (Fig. 7). The Infrared spectra of the purified antimicrobial substance showed the presence of six peaks at 3389, 2928, 1629, 1602, 1410, and $1078 \mathrm{~cm}^{-1}$ (Fig. 8), these peaks according to Pavia [29] explanation indicated the presence of hydroxyl group at $3389 \mathrm{~cm}^{-1}$, aliphatic $\mathrm{C}-\mathrm{H}$ at $2928 \mathrm{~cm}^{-1}$, amide $\mathrm{C}=0$ at $1629.90 \mathrm{~cm}^{-1}$, aromatic $\mathrm{C}=\mathrm{C}$ at $1602 \mathrm{~cm}^{-1}$, aliphatic $\mathrm{C}-\mathrm{H}$ at 1410 $\mathrm{cm}^{-1}$, and -CO- group at $1078.24 \mathrm{~cm}^{-1}$. All these peaks are present in antibiotics related to glycopeptide group [26,30]. Depending on all the above characteristics, the antimicrobial substance produced from P. alni may be regarded as glycopeptide antibiotic.

The presence of hydroxyl group at 3389/cm, aliphatic C-H at 2928/cm amide $\mathrm{C}=\mathrm{O}$ at $1629.90 / \mathrm{cm}$, aromatic $\mathrm{C}=\mathrm{C}$ at $1602 / \mathrm{cm}$, aliphatic $\mathrm{C}-\mathrm{H}$ at $1410 / \mathrm{cm}$ and -CO-group at 1078.24/cm (Fig. 8).

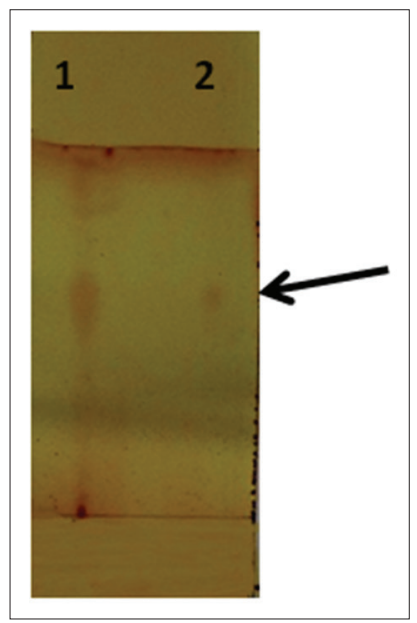

Fig. 6: Thin layer chromatography of purified antimicrobial substance produced from Pseudonocardia alni using the mobile system butanol: acetic acid: water (3:5:7); $\mathbf{R}_{\mathrm{f}}=\mathbf{0 . 5 3}$. (1) crude extract, and (2) purified active substance
The biological activities of the partially purified bioactive substance

The purified bioactive substance revealed to have antibacterial and antifungal activities against $S$. aureus, which reached $35 \mathrm{~mm} / 30 \mu \mathrm{g}$ of purified antimicrobial substance when compared with standard antibiotic vancomycin, which appeared activity $25 \mathrm{~mm} / 30 \mu \mathrm{g}$ of vancomycin (data not shown) but it had no activity against Gramnegative bacteria such as Morganilla morganii. In addition, the purified substance showed activity against pathogenic fungal T. mentagrophyte (Fig. 9).

In addition, cytotoxic activity of purified substance and crude filtrate was assayed by MTT method using the human breast cancer cell line (MCF-7cell line) and the normal human hepatic cells (non-tumorigenic fetal hepatic cell line [WRL-68]). The results showed that the purified extract had cytotoxic activity as showed in Fig. 10. From our results, it was revealed that the purified metabolite $(100 \mu \mathrm{g} / \mathrm{ml})$ had the ability to inhibit breast cancer cell line (MCF-7) at a percentage up to $23.7 \%$, whereas it slightly inhibited normal hepatic cell line (WRL-68) at $7.64 \%, p=0.0005$. Many studies reported that the actinobacterial species had the ability to produce a wide spectrum of antimicrobial agents and anticancer metabolites that had capability of inhibiting cancer cell lines in comparison with other sources such as plant products that have antioxidant activity and they inhibit cancer cell lines $[1,4,31,32]$.

\section{CONCLUSION}

Antibiotic production of $P$. alni is variable under different production parameters. Therefore, the formulation of production medium using different sources of carbon, nitrogen, and phosphate salts, as well as optimization of the growing conditions is one of the essentials that must be followed to improve the production of antibiotics from this organism. The bioactive product showed novel activity as antibacterial, antifungal, and anticancer properties.

\section{ACKNOWLEDGMENTS}

This work was performed at Biotechnology and Genetic Engineering Laboratory, Biology Department, College of Science, Babylon University. All apparatus and some experimental requirements were supported by the college.

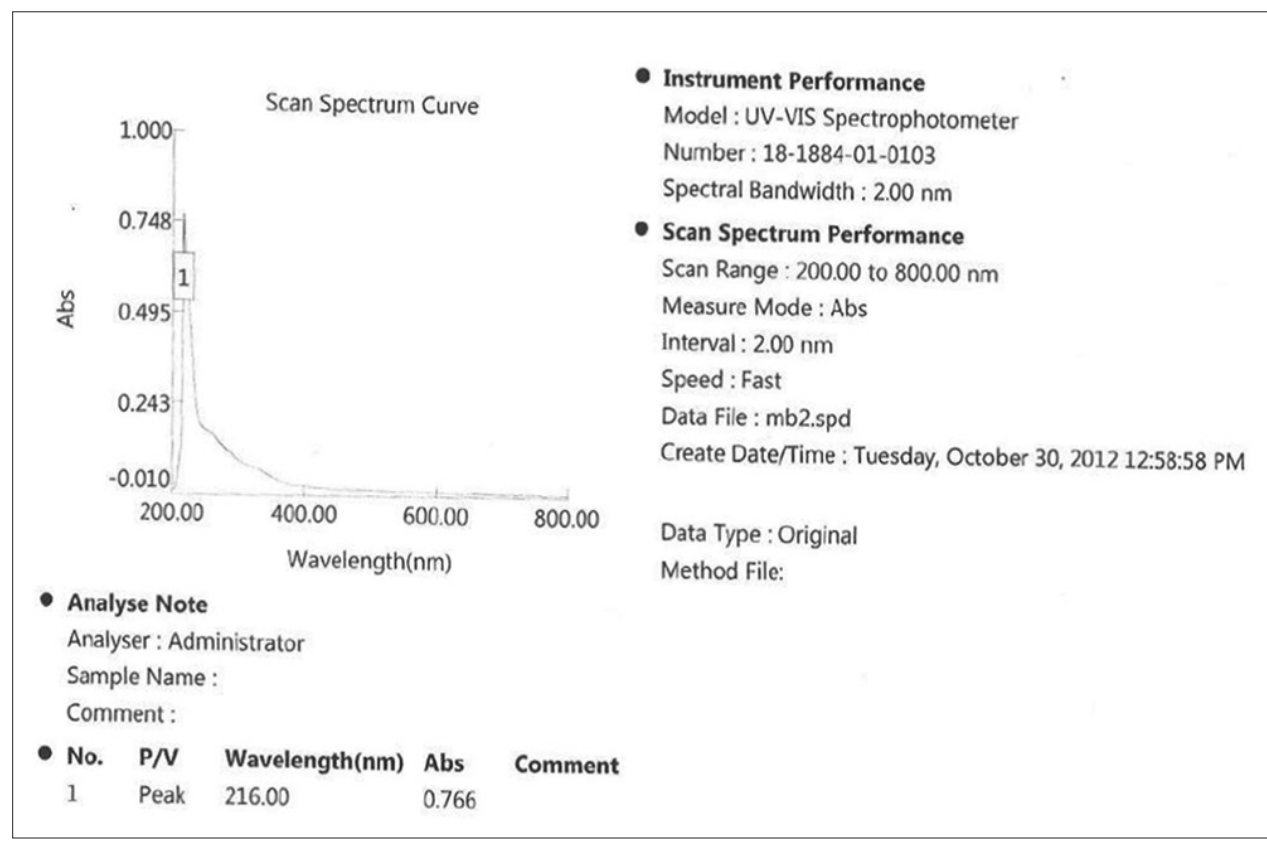

Fig. 7: The ultraviolet-spectra of purified antimicrobial substance produced from Pseudonocardia alni with the $\lambda$ max $216 \mathrm{~nm}$ 


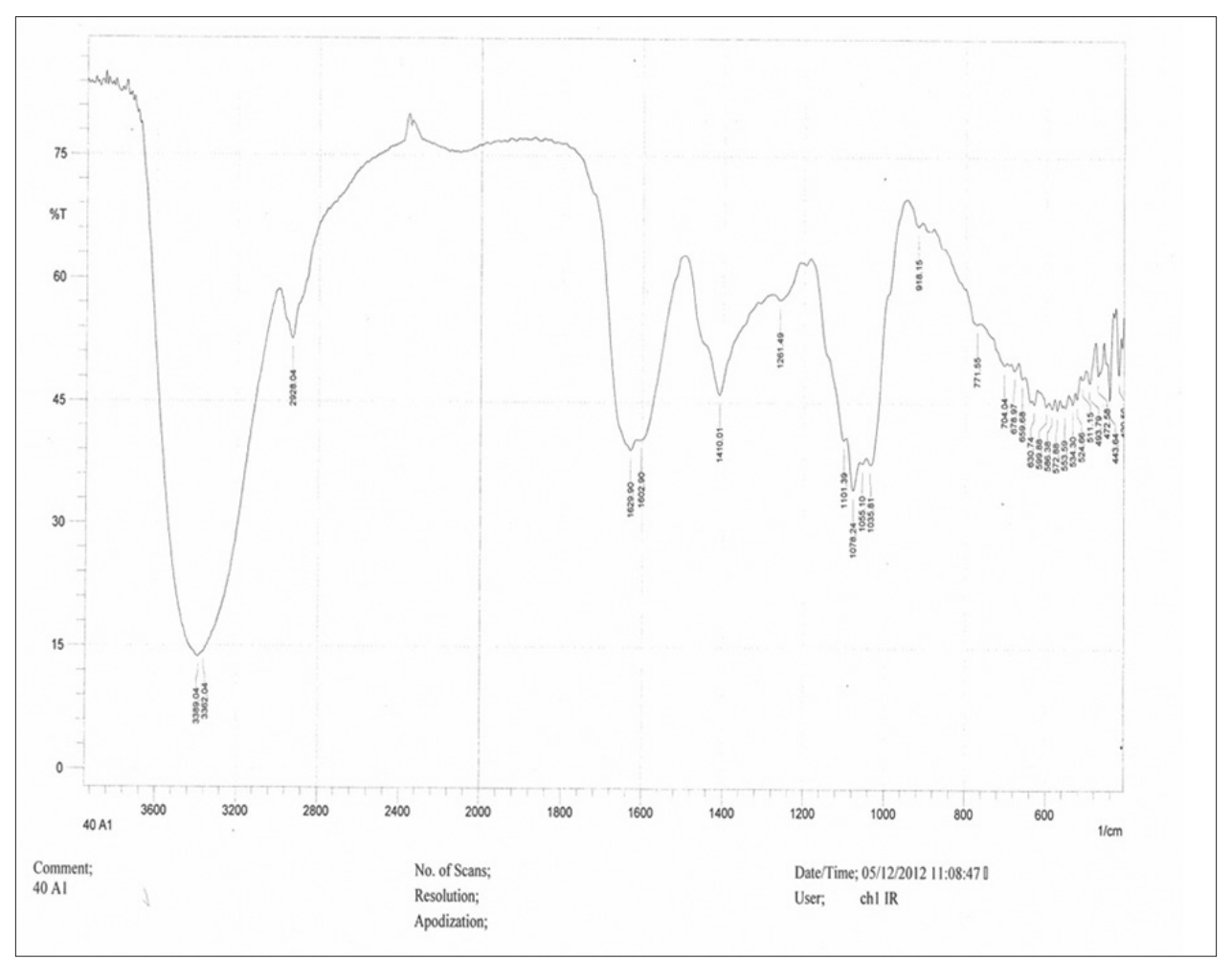

Fig. 8: Fourier transforms infrared spectra of purified active substance produced from Pseudonocardia alni

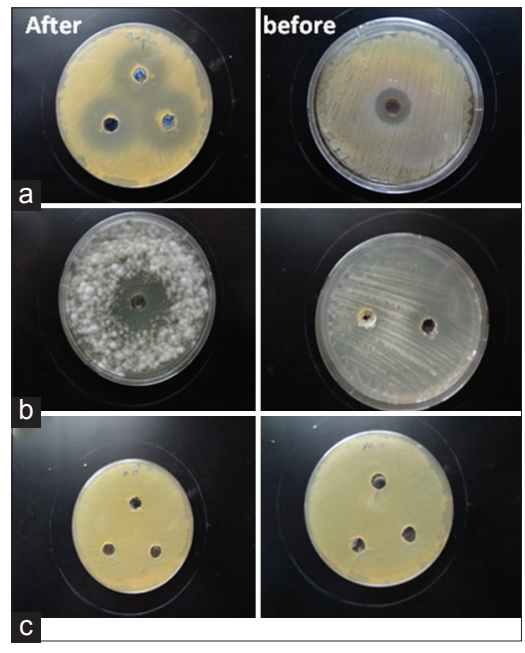

Fig. 9: The antimicrobial activity of the metabolite produced from Pseudonocardia alni against pathogenic bacteria and fungus before and after purification. (a) Staphylococcus aureus,

(b) Trichophyton mentagrophyte, (c) Morganella morganii. Antimicrobial activity was performed using $100 \mu \mathrm{l}$ of filtered supernatant of $P$. alni culture and purified antimicrobial agent

(both containing $30 \mu \mathrm{g}$ of an antimicrobial substance)

\section{REFERENCES}

1. Newman DJ, Cragg GM. Natural products as sources of new drugs over the last 25 years. J Nat Prod 2007;70(3):461-77.

2. Gehlot V, Mahant S, Das K, Das R. Most of the Helicobacter pylori isolates are resistant to levofloxacin in north India. Int J Pharm Pharm Sci 2016;8(1):454-6.

3. Gehlot V, Mahant S, Vijayraghwan P, Das K, Hoda S, Das R. Therapeutic potential of lichen Parmeliaperlata against dual drag-resistant Helicobacter pylori isolates. Int J Pharm Pharm Sci 2016;8(1):205-8.

4. Bérdy J. Bioactive microbial metabolites. J Antibiot (Tokyo)

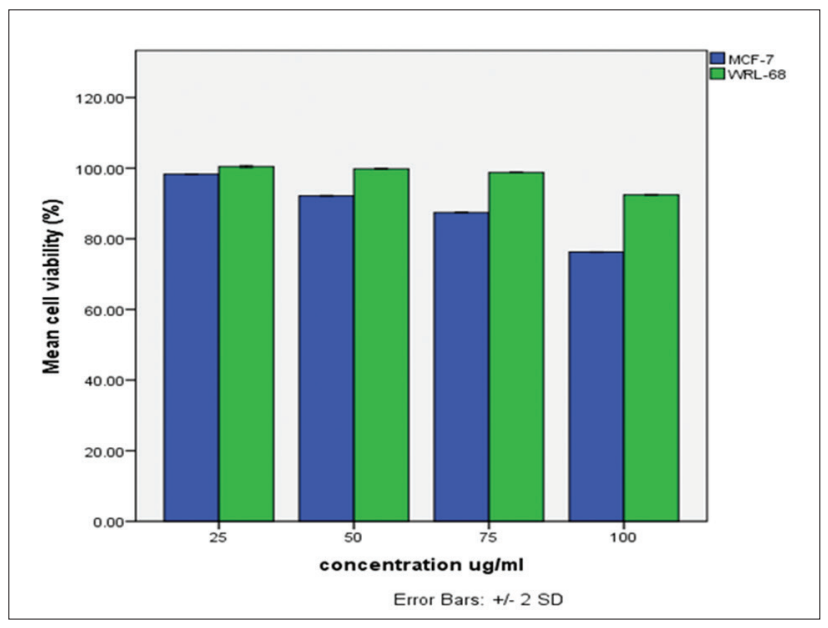

Fig. 10: The cytotoxic activity of purified active substance $(100 \mu \mathrm{g} / \mathrm{ml})$ of Pseudonocardia alni against breast cancer cell line Michigan Cancer Foundation-7 and the normal hepatic cell line WRL-68

2005;58(1):1-26.

5. da Silva IR, Martins MK, Carvalho CM, de Azevedo JL, de Lima Procópio RE. The effect of varying culture conditions on the production of antibiotics by Streptomyces spp., isolated from the Amazonian soil. Ferment Technol 2012;1:105.

6. Usha Kiranmayi M, Sudhakar P, Sreenivasulu K, Vijayalakshmi M. Optimization of culturing conditions for improved production of bioactive metabolites by Pseudonocardia sp. VUK-10. Mycobiology 2011;39(3):174-81

7. Omran R, Kadhem MF. Isolation and identification of antibioticproducing actinomycetes. J Babylon Univ 2012;22(1):285-92.

8. Shirling EB, Gottlieb D. Methods for characterization of Streptomyces species. Int J Sys Bacteriol 1966;16(3):313-40.

9. Perez C, Pauli M, Bazevque P. An antibiotic assay by the agar-well diffusion method. Acta Biol Med Exp 1990;15:113-5.

10. Pavia DL, Lampman GM, Kriz GS, Vyvyan JR. Microscale and 
Macroscale Techniques in the Organic Laboratory. USA: Brooks/Cole; 2002.

11. Mohanty S, Basu S. Fundamentals of Practical Clinical Biochemistry New Delhi. India: BI Publications Pvt.; 2006. p. 282.

12. Augustine SK, Bhavsar SP, Baserisalehi M, Kapadnis BP. A nonpolyene antifungal antibiotic from Streptomyces albidoflavus PU 23. Indian J Exp Biol 2006;42:928-32.

13. Freshney RI. The Culture of an Animal Cell. $6^{\text {th }}$ ed. New York: WilyLiss; 2010.

14. Chih PL, Wei JT, Yuang LL, Yuh CK. The extracts from Nelumbo nucifera suppress cell cycle progression, cytokine genes expression, and cell proliferation in human peripheral blood mononuclear cells. Life Sci 2004;75:699-16.

15. Omran R. Corrosive lesions at concrete infrastructures as promising source for isolating bioactive actinobacteria. Am J Life Sci 2015;3(4):247-56.

16. Ripa FA, Nikkon F, Zaman S, Khondkar P. Optimal conditions for antimicrobial metabolites production from a new Streptomyces sp. Rupa08pr isolated from Bangladeshi soil. Mycobiology 2009;37(3):211-4.

17. Raytapadar S, Paul AK. Production of an antifungal antibiotic by Streptomyces aburaviensis IDA-28. Microbiol Res 2001;155(4):315-23.

18. Aharonowitz Y, Demain AL. Influence of inorganic phosphate and organic buffers on cephalosporin production by Streptomyces clavuligerus. Arch Microbiol 1977;115(2):169-73.

19. Alduina R, Lo Piccolo L, D'Alia D, Ferraro C, Gunnarsson N, Donadio S, et al. Phosphate-controlled regulator for the biosynthesis of the dalbavancin precursor A40926. J Bacteriol 2007;189(22):8120-29.

20. Demain AL, Matteo CC. Phenylalanine stimulation of gramicidin S formation. Antimicrob Agents Chemother 1976;9(6):1000-03.

21. Thumar JT, Dhulia K, Singh SP. Isolation and partial purification of an antimicrobial agent from halotolerant alkaliphilic Streptomyces aburaviensis strain Kut-8. World J Microbiol Biotechnol 2010;26:2081-7.

22. Fiedler H, Dieter A, Hamm A, Goodfellow M, Muller WE, Brun R, et al. Pyrocoll an antibiotic, antiparasitic and antitumor compound produced by a novel alkaliphilic Streptomyces strain. J Antibiot 2003;56(7):639-46.

23. El-Naggar MY, Hassan MA, Said WY, El-Aassar SA. Effect of support materials on antibiotic MSW2000 production by immobilized Streptomyces violatus. J Gen Appl Microbiol 2003;49(4):235-43.

24. Miyoshi $T$, Iseki $M$, Konomi $T$, Imanaka $H$. Biosynthesis of bicyclomycin. I. Appearance of aerial mycelia negative strains (am-). J Antibiot (Tokyo) 1980;33(5):480-7.

25. Traub WH, Leonhard B. Heat stability of the antimicrobia activity of sixty-two antibacterial agents. J Antimicrob Chemother 1995;35(1):149-54.

26. Oskay M. Isolation and purification of two metabolites (KGG32-A \& KGG32-B) from a soil bacterium, Streptomyces sp., KGG32. Int J Agric Biol 2011;13(3):369-74.

27. Lorian V. Antibiotics in Laboratory Medicine. USA: Lippincott Williams and Wilkins; 2005. p. 654.

28. Zhang C, Li S, Tian X, Niu S, Zhang W, Chen Y, et al. Pseudonocardians AC, new diaza anthraquinone derivatives from a deep-sea actinomycete Pseudonocardia sp. SCSI 01299. Mar Drugs 2011;9(8):1428-39.

29. Pavia DL, Lampman GM, Kriz GS, Vyvyan JR. Introduction to Spectroscopy. USA: Brooks/Cole; 2009.

30. Takeuchi M, Enokita R, Okazaki T, Kagasaki T, Inukai M. Helvecardins $\mathrm{A}$ and $\mathrm{B}$, novel glycopeptide antibiotics I. Taxonomy, fermentation, isolation and physico-chemical properties. J Antibiot (Tokyo) 1991;4(3):263-70.

31. Jeena K, Liju VB, Kuttan R. Antitumor and cytotoxic activity of ginger essential oil (Zingiber officinale roscoe). Int J Pharm Pharm Sci 2015;7(8):341-44.

32. Thanekar DR, Tupe P, Dhodi J, Juvekar AR. Evaluation of in vitro cytotoxic activity of petroleum ether and methanol extract of Mentha arvensis (whole plant) on human cancer cell lines. Int J Pharm Pharm Sci 2014;6(8):169-72. 